\title{
Operational Features of the Macroeconomic Developments in Kyrgyzstan and Its Implications for Xinjiang
}

\author{
Ahbuduhani Awuti \\ Human Resource Research Institute \\ Urumqi Vocational University \\ Urumqi, China 830002
}

\begin{abstract}
Taking GDP of Kyrgyzstan ${ }^{(1)}$ as main line, this article respectively researches the influence degree of consumption, investment, net export, exchange rate and unemployment rate indicators on GDP, analyzes the current situation of economic development of the country as well as the driven factors and bottleneck factors and comes to conclusions as follows: firstly, the resident and governmental consumption play a positive promoting function for Kyrgyzstan's GDP and the function of governmental consumption is larger than resident consumption in promoting its GDP; secondly, the increase of investment amount greatly promotes the economic development of Kyrgyzstan; thirdly, for short term, the function of consumption is larger than investment in promoting economic growth, while for long term, the positive effect of investment on GDP is larger than the positive promoting function of consumption, and the lag phase is 3 years; fourthly, exchange rate has slight influence on GDP growth rate, while unemployment rate obviously has negative influence on the growth rate of GDP; fifthly, net export obviously has a positive influence on GDP. In accordance with the result, it provides basis of our investment abroad and import/export decision for reference.
\end{abstract}

Keywords - economic development; factor; quantitative analysis, Kyrgyzstan

\section{PROBLEM DESCRIPTION}

Since establishment of diplomatic relation in 1992, the economic and trade cooperation between China and Kyrgyzstan has roughly experienced rapid growth, stable growth after fall as well as rapid and stable growth steps. The scale of trade trends to expand as a whole, in particular, within the cooperation frame of WTO and SCO for recent years, the China and Kyrgyzstan bilateral trade has obtained considerable development. Based on the statistics of ADB, the ChinaKyrgyzstan trade value of 2011 is 5298 million dollar, $3.11 \%$ more than the previous year, including 5242 million dollar of import from China, growing 3.29\%; 55.42 million dollar of export to China, growing $-11.11 \%$. China becomes the second largest trade partner country of Kyrgyzstan, the first largest country of origin and the fourth largest exporting country.

Hereinafter referred to as "Kyrgyzstan".
Kyrgyzstan is making great efforts to abstract foreign investment and hopes to inject new motive force of development to its economy through introduction of foreign investment. As an economic giant adjacent to Kyrgyzstan, China becomes the second largest trade partner in addition to Russia and the object for attracting foreign investment as well in the nature of things. However, due to the undesirable investment environment of Kyrgyzstan, e.g. seriously delayed basic infrastructure, unstable political situation, incomplete national legal system, randomness of policy, occurrence of non-performance of contract, phenomenon of seriously skimping the profit of foreign enterprises and non-free convertibility of money, the production investment enterprises are unwilling to invest Kyrgyzstan, which also is the ultimate reason for less economic and technical cooperation between both parties.

In terms of current market situation of Kyrgyzstan, its area is only 198.5 thousand square kilometer, lived no more than 5.6 million people with relatively low income level, so that it has small amount of income and not that large amount of consumption correspondingly. With the successively occurrence of financial crisis and European debt crisis, in face of current situation of weak development of global economy, all countries are influenced by the global economic situation. Kyrgyzstan slows down its speed of economic development, resulting in serious unemployment and improper phenomenon in industrial structure; however, it possesses abundant mine resources and beautiful nature scenery, hence, how to convert resources into economic strength through effective policy should be the problem to be paid on special attention by Kyrgyzstan government.

As an important belt for trading between China and countries in Central Asia, Xinjiang plays a role of bridge tower in our country actively participating in central Asia regional cooperation; while in the development of Kyrgyzstan in recent years, it is complementary with Xinjiang in terms of agriculture resources and technical development. In China-Kyrgyzstan trade, the trade between Xinjiang and Kyrgyzstan occupies a decisive position; ${ }^{(2)}$ as an important link of reopening "the Silk

Fanzi. Topic on China-Kyrgyzstan Boundary Trade by Kyrgyzstan Commercial Counselor Stationed in China [J]. NEW SILK ROAD HORIZON, 
Road" of China, it has strong practical significance to conduct empirical research on Kyrgyzstan. ${ }^{3}$

Through analysis on the quantitative relation of economic variable selected by Kyrgyzstan, we can learn the situation and influence factors of macroeconomic development of that country, provide reference basis for the country to fully play the comparative advantage of economy and promote the benefit of resource allocation; in the meanwhile, according to the analysis result of Kyrgyzstan's macroeconomic influence, it also provides reference for our government departments and enterprise departments to make decisions concerning investment, export and import to Kyrgyzstan.

\section{DATA SELECTION AND PROCESS}

In order to learn the current situation of macro economy of Kyrgyzstan, the article selects the indicators of GDP, consumption, net export, fixed asset investment, unemployment rate and exchange rate, etc. to respectively analyze their influences on the economic development. In economic aspect, the actual GDP is an important representative indicator reflecting the economic development situation of a country, and as the most overall descriptive variable at present, it is used to describe the operational situation of macro economy of countries and regions all the time; consumption and investment are the important components of economic growth and the significant factor influencing GDP; with the issuance of trade preferential policies related, international trade becomes an important avenue to promote the economic development of Kyrgyzstan; hence, it introduces the variable of net export into the model to inspect the quantitative relation between GDP and effect variables related. In order to eliminate the influence of price factor on empirical analysis, this article practically processes the data. Through analysis on the macro economy of the country, understand the main factors influencing the economic growth of the country, so as to find the breakthrough point promoting the economic growth of the country and bottleneck point hindering economic growth. The sample division of the article is the economic data of Kyrgyzstan over years of 1995-2014 and the data are from the statistic information published by Asian Development Bank (ADB), International Monetary Fund (IMF) and other international organizations.

From the perspective of demand, GDP mainly composes of consumption (including governmental consumption and resident consumption), investment, net export (the following will divide it into import and export parts) three parts; hence, firstly it inspects the effect of component factors on Kyrgyzstan GDP from the annual average growth rate of each indicator "Table 1".
TABLE I. AVERAGE GROWTH RATE OF GDP AND ITS COMPONENT FACTORS OF KYRGYZSTAN OF 1995-2014 (UNIT: \%)

\begin{tabular}{lccccc}
\hline GDP & $\begin{array}{c}\text { Govern } \\
\text { mental } \\
\text { consump } \\
\text { tion }\end{array}$ & $\begin{array}{c}\text { Resident } \\
\text { consumption }\end{array}$ & $\begin{array}{c}\text { Invest } \\
\text { ment }\end{array}$ & Export & Import \\
\hline 4.36 & 4.08 & 4.99 & 6.28 & 15.97 & 18.43 \\
\hline \multicolumn{7}{c}{ Note: all the growth rates of the indicators therein are geometric averages. }
\end{tabular}

As we can learn from the calculation results of the table, the annual growth rates of both import and export are relatively faster, mainly due to the fact that Kyrgyzstan just walked away from the brink of economic collapse in 1995, having a thousand things wait to be done, and due to historical and practical factors, its industrial system is not complete and it needs to import a large number of technologies and equipment from foreign countries to develop its domestic economy; on the other hand, its annual growth rate of import is higher than export, and Kyrgyzstan mainly produces agricultural products to meet consumption of its own country, while its export of energy resources is limited due to poor means of transportation; hence, the growth rate of import is far higher than its export. In addition, as a typical agricultural giant, Kyrgyzstan's serious imbalance of industry and agriculture is a reason resulting in deficit.

Secondly, although its import and export grow in higher speed, their comprehensive influence on GDP is not the greatest. From the table we learn that, although the growth rate of gross capital formation ranks third, its rate of contribution to GDP is the largest. During the research on the samples herein, the average growth rate of gross capital formation reaches $6.28 \%$, obviously exceeding the growth rate of GDP and has an extremely great positive promoting function. This is mainly because that, on one hand, as an undeveloped agricultural giant, in order to promote the economic development of Kyrgyzstan, the government can only increase investment to promote a long-term economic development at the cost of sacrificing current consumption. On the other hand, since Kyrgyzstan government actively promotes the policy of introduction of foreign capital, its ability of attracting foreign capital further increases and foreign investment grows faster, which leads to a development trend of obviously speed-up increasing investment amount.

Thirdly, the average growth rate of total consumption is $4.36 \%$, and the growth rate of resident consumption is higher than which of governmental consumption (i.e. the average growth rate of resident consumption is $4.99 \%$ and the governmental consumption is $4.08 \%$ ). It meets the requirements of economic development, and due to the fact that the main consumption target group of a country is resident consumption which directly relates to the development scale of the country and benefit level of its people; therefore, the speedup increasing of resident consumption contributes to the development of its national economy and rise of well-being degree of its people.

\footnotetext{
2007, (06).

${ }^{(3)} \mathrm{Xu}$ Hui. Economic and Trade Cooperation between China and Kyrgyzstan

[J]. Russian Central Asian \& East European Market, 2007,(07)
} 


\section{ANALYSIS OF EMPIRICAL RESULT}

\section{A. Analysis on the Quantitative Relation Between GDP and Consumption}

This article divides consumption into governmental consumption and resident consumption two indicators to further analyze their degree of influence on GDP; hence, the binary double-log model of GDP and governmental and resident consumptions are fitted as follows:

$$
\begin{aligned}
& \ln G D P=0.36+\underset{\left(5.75^{* *}\right)}{0.39} \ln R C 1+\underset{\left(4.82^{* * *}\right)}{0.54} \ln U C 1 \\
& \bar{R}^{2}=0.99, D W=1.86, F=650
\end{aligned}
$$

(Note: RC1 refers to the amount of resident consumption, UC1 refers to the amount of governmental consumption; (.) refers to t statistic, "**" and "**" respectively refer to that the coefficients are under the outstanding level of $5 \%$ and $1 \%$; the lag phase of indicators in model and the introduction and elimination of other variables shall all obey the principles of $\max . \overline{R^{2}}$, max. F inspection value and min. SIC and SC, etc. the same below.)

From the model we can see that the resident and governmental consumptions all play a positive promoting function for the practical GDP of Kyrgyzstan, which is in line with their economic meanings that as components of GDP, the amount of resident and governmental consumptions directly influence the amount of its GDP.

In the consumption of Kyrgyzstan, the governmental consumption has a big promoting function for its GDP, the governmental consumption elasticity of practical GDP is 0.54 , i.e. when the governmental consumption rises $1 \%$, it can practically drive GDP to increase $0.54 \%$; while the resident consumption elasticity is 0.39 only. This is because the economic basis of Kyrgyzstan is quite weak, the income level and consumption ability of residents are limited, lots of largescale projects and expenditures are borne by the government, so that in terms of promoting economic growth, governmental consumption is higher than resident consumption; on the other hand, due to autarky of Kyrgyzstan's economic form, the consumption data of most residents are not convenient for statistic, the resident consumption amount used in the regression result is obviously lower than true level; hence, the resident consumption elasticity of GDP is low. Therefore, in the case of unchanged actual total consumption, it can properly increase the proportion of governmental consumption, reduce amount of resident consumption, so as to increase its GDP. ${ }^{(4)}$

\section{B. Analysis on Quantitative Relation between GDP and Investment}

In this model, it divides fixed asset into two parts: domestic investment and foreign investment and conducts quantitative analysis on the two investment methods for purpose of analyzing the promotion function of both parts on Kyrgyzstan GDP, the lag phase of influence of investment on GDP as well

\footnotetext{
(4) E.g. implemented double prime policy of import imposition and export subsidy.
}

as Kyrgyzstan's ability of attracting foreign capital. The double-log equation of two variables it fitted is as follows:

$$
\begin{aligned}
& \ln G D P_{\mathrm{t}}=3.185 \underset{\left(17.42^{* * *}\right)}{0.73} \ln I_{1 t} \underset{\left(-3.37^{* * *}\right)}{0.083} \ln I_{2 t-3}+\varepsilon_{t} \\
& \overline{R^{2}}=0.97, D W=2.16, F=159
\end{aligned}
$$

(Note: I1 refers to domestic investment; 2 refers to foreign investment; $t-i$ refers to the lag-i phase variable of variables, e.g. $I_{2 \mathrm{t}-3}$ refers to the foreign investment of lag three phases, the same below.)

From the model we can see that, the economic development and domestic investment of Kyrgyzstan have obvious positive relation. Every $1 \%$ increased of domestic investment it will cause $0.73 \%$ increased of domestic GDP; however, foreign investment has negative function to GDP seen from the model that every $1 \%$ increased of foreign investment, it will cause a reverse change of $0.083 \%$ of domestic GDP.

The domestic investment of Kyrgyzstan has positive promoting function to GDP while foreign investment has to certain degree negative hindering function to GDP. The positive promoting function of domestic investment on GDP meets fact, while the negative effect of foreign investment on Kyrgyzstan GDP is not in line with most countries, by combining with the actual situation of Kyrgyzstan, it is mainly because that the utilization efficiency of Kyrgyzstan on foreign investment is not high enough, due to major causes in process of foreign investment as well as its poor ability of undertaking foreign investment. In order to promote economic development, on one hand, Kyrgyzstan should make efforts to promote growth of domestic investment; on the other hand, it should effectively take advantage of foreign investment, avoid corruption and waste behaviors in process of foreign investment and introduce advanced equipment technologies and management experience by foreign investment.

In addition, the negative promoting function of foreign investment to GDP has lag phase for 3 years. In economic practice, the utilization of foreign investment requires for certain lag; in the meanwhile, the foreign investment is mainly on equipment and technologies, so that it has lag effect on the influence of economic development.

\section{Analysis on the Quantitative Relation between GDP and Consumption \& Investment}

This model brings into both total consumption and total investment of Kyrgyzstan to comprehensively consider their degree of influence on actual GDP of Kyrgyzstan.

$$
\begin{aligned}
& \ln G D P_{t}=1.69+\underset{\left(7.88^{* * *}\right)}{0.78} \ln C_{t} \underset{\left(-2.225^{* * *}\right)}{-0.38} \ln C_{t-2}+\underset{\left(2.9^{* *}\right)}{0.24} \ln I_{t}+\underset{\left(2.11^{*}\right)}{0.21 \ln I_{t-3}} \\
& \overline{R^{2}}=0.99, D W=1.97, F=219
\end{aligned}
$$

From the model we can see that, in the short term, the promoting function of Kyrgyzstan consumption on its economic growth is far more than the influence of investment; while in the long term, the positive promoting effect of investment on GDP is larger than consumption. The short-term 
elasticity of total consumption is 0.78 , the long-term elasticity is 0.405 ; while when $1 \%$ increased of current total investment, it will cause $0.237 \%$ increased of current actual GDP and $0.212 \%$ increased of GDP lag for 3 years, i.e. the short-term elasticity and long-term elasticity respectively are 0.237 and 0.449. It means that, in short term, the economic development of Kyrgyzstan mainly driven by consumption and the shortterm influence of consumption is larger than its long-term influence; however, its long-term development is mainly based on investment. This is in line with the economic practice, in particular, for agricultural giant like Kyrgyzstan, most industries of the country are used for resident consumption, its economy is mainly driven by consumption, but due to insufficient agricultural development level, it requires making great efforts to introduce investment, purchasing advanced production equipment and technologies; hence, in the long term, it requires increasing investment and promoting its economic development.

\section{Analysis on Quantitative Relation between Gdp and Unemployment \& Exchange Rate}

In order to prevent autocorrelation in model from influencing the empirical effect, the writer converts the practical GDP into growth rate, denoted by gdp, and the result is as follows:

$$
\begin{aligned}
& \operatorname{lngdp}=2.64+\underset{(0.55)}{0.71 \ln e-6.69} \ln U R \\
& \left.\overline{R^{2}}=0.2 .11^{* * * *}\right) \\
& 0.84, D W=2.17, F=284
\end{aligned}
$$

(Where, the e refers to exchange rate, UR refers to unemployment rate.)

From the formula above we can see that, the growth rate of exchange rate on GDP is not significant, but the significant influence of unemployment rate on GDP is negative. Where, the coefficient before lne is 0.71 , referring to every $1 \%$ increased of exchange rate, correspondingly the GDP growth rate will rise $0.71 \%$, but under significance level of $5 \%$, the coefficient $\mathrm{T}$ does not pass the test, so that it has no significant influence. The coefficient before unemployment is -6.69 , means that the employment situation of Kyrgyzstan decides its economic growth to a great extent, the higher unemployment rate is, the lower GDP growth rate of Kyrgyzstan is. Employment of a certain proportion is the precondition of economic growth and the guarantee of social stability, so that in the initial step of economic development, at the same time of remaining employment rate to certain degree, Kyrgyzstan shall improve the quality of employees to promote its economic development.

\section{E. Analysis on Quantitative Relation between GDP and Net Export}

As an inland country, most domestic demands of Kyrgyzstan depend on import, and its development of dominant industries, e.g. electric resources, precious metal industry and agriculture, mostly depends on export for earning foreign exchange. ${ }^{(5)}$ Hence, it has certain practical significance

\footnotetext{
${ }^{(5)}$ Li Qin, Xu Yunxia. Exploration and Analysis on Xinjiang Devoting Great
}

to research net export on its GDP, the simulated results are as follows:

$$
\begin{aligned}
& \ln G D P_{t}=3.14+\underset{\left(16.14^{* * *}\right)}{0.862} \ln E X_{t} \underset{\left(-2.03^{*}\right)}{0.173 \ln E X_{t-3}} \\
& \overline{R^{2}}=0.99, D W=2.2, F=415
\end{aligned}
$$

(Note: where, EX refers to net exports.)

Net export has obvious positive influence on GDP in short term, but its lag influence is negative. Every $1 \%$ increased of net export, the actual GDP increases $0.73 \%$, which mean that the net export of Kyrgyzstan has a large promotion on economy. The export commodities of Kyrgyzstan is with single structure, mainly based on precious metal, mine products, textiles and other raw materials; its export objectives include: Asia area: China, United Arab Emirates, Uzbekistan, Turkey and Tajikistan; in European area: Switzerland, Russia, France, etc. Such structure of commodities imported and exported is obviously not reasonable, the additional valve of product exported is low while all the imported are rigid demands for its development; hence, such import and export mode is urgently needed to be changed.

On the whole, the influence of net export on GDP is obviously positive. The long-term elasticity of net export is $0.689>0$, which means that, in the long term, net export has obvious promoting function on the growth of its GDP. In the meanwhile, it should fully play the complementarity and mutual benefit function with our country in agricultural trade.

\section{MAIN CONCLUSIONS AND ITS IMPLICATIONS FOR XINJIANG}

\section{A. Main Conclusions}

Through analysis on the empirical results, it comes to conclusions as follows:

First of all, the resident and governmental consumption play a positive promoting function for Kyrgyzstan's GDP and the function of governmental consumption is larger than resident consumption in promoting its GDP. During sample research by the article, Kyrgyzstan enlarges public consumption mainly using for public infrastructure construction, the initial stage of increasing governmental consumption has larger promoting function to economy.

Secondly, the domestic investment has positive promoting function to GDP, foreign investment has certain negative hindering effect on GDP, and positive elasticity effect of domestic investment is larger than the negative hindering effect of foreign investment, i.e. the investment amount has positive promoting function for Kyrgyzstan's actual GDP.

Thirdly, in the short term, the promoting function of Kyrgyzstan consumption on economic growth is far larger than the influence of investment; while, in the long term, the positive promoting effect of investment on GDP is larger than the promoting effect on consumption, which is in line with the

Efforts to Export to Kyrgyzstan and Countermeasures [J]. Russian Central Asian \& East European Market, 2010, (02). 
economic theory that, in the short term, it directly drives the increase of actual GDP due to increase of consumption, reversely, the promoting effect of investment requires certain period to show the effect, having lag effect of promotion by investment and the lag period is 3 years. To figure out the reason, Kyrgyzstan's economic basis is still weak, still in the initial step of industrialization, with low degree of industrialization, small additional value of industries, low starting point and small quantity of modern hi-tech industries; in addition, its technical level and technological content of industries are still low and the whole industrial structure is still in processing stage of industrial structure at low level.

Fourthly, exchange rate has slight influence on GDP growth rate, while unemployment rate obviously has negative influence on the growth rate of GDP. The main reason why is that high unemployment rate means decline of employees of the country, further causes reduction of labors, i.e. small labor investment, which may ultimately lead to small newly added GDP.

Fifthly, net export obviously has a positive influence on GDP. Since the net export is the difference of export amount and import amount, the larger net export is the larger the export amount is, the increase of export amount directly causes increase of GDP; in the meanwhile, the increase of export can correspondingly increase the introduction of foreign hi-tech products and technologies, and further drive the increase of actual GDP.

\section{B. Its Implications for Xinjiang}

In conclusion, through analysis on the GDP and its influence factors of Kyrgyzstan as well as the current situation of development of Kyrgyzstan on the whole, we find some problems existing in economic development, which provides the following policies and suggestions for Xinjiang Government departments and enterprises:

Firstly, export expansion of hi-tech products and advanced technologies of Kyrgyzstan. Since Kyrgyzstan consumption has significant promoting effect on its GDP, it must promote the growth through increase of consumption; however, as a typical agricultural giant, Kyrgyzstan's hi-tech level is weak, which is ultimately unable to meet the demand of Kyrgyzstan for hi-tech products; hence, Kyrgyzstan requires importing a large number of hi-tech products to meet domestic demands. Thus, it provides a quite large space for hi-tech product enterprises overseas, and as an important trade partner, Xinjiang must seize the opportunity and utilize the advantage of being adjacent to Kyrgyzstan to export a large number of mechanical equipment, electronics, household appliance and other hi-tech products with high additional value and hi-tech contents. Through the analysis on the quantitative relation between Kyrgyzstan GDP and consumption, the GDP growth rate promoted by Kyrgyzstan's resident consumption is lower than governmental consumption, this is mainly because the economic foundation of Kyrgyzstan is quite weak, the income level and consumption ability of resident are limited, so that there is little space to promote GDP growth rate by increase of resident consumption and only increase of Kyrgyzstan's governmental consumption can it promote the economic growth; therefore, most large-scale project and expenditure are borne by government, and governmental consumption is mainly used in technology innovation, architecture and other infrastructure construction which require support of high technology; however, Kyrgyzstan's development level of high technology is relatively low, to carry out these projects requires import of high technologies and introduction of a large batch of senior talents, and Xinjiang has possessed all they need, so that our government departments and enterprises should seize the opportunity to make great efforts to export high technologies and talents to Kyrgyzstan.

Secondly, increase the investment degree to Kyrgyzstan. In terms of domestic environment of Kyrgyzstan, the president of Kyrgyzstan signed the executive order to hold the post of prime minister of the new government on September 6, 2012, which means the whole political environment of Kyrgyzstan trends to stability. In this aspect, investment to Kyrgyzstan obtains favorable external environment, and as we know, political stabilization is the foundation of investment, so that the political risk is not large as previous. Through analysis on the quantitative relation between Kyrgyzstan GDP and investment, in the short term, the effect of promoting GDP by consumption is larger than investment, however, in the long term, the investment is larger than consumption; hence, to truly improve the growth rate of GDP requires making efforts to attract investment, purchasing advanced production equipment and technologies, so that from the perspective of long-term strategy of Kyrgyzstan, the space of investment to Kyrgyzstan is large. The economic development of Kyrgyzstan is still at relatively low level, especially the development of industry and the third industry requiring depending on investment, while in terms of the domestic investment level of Kyrgyzstan at present, it is very difficult to improve GDP growth only through developing these pillar industries, since the current technological level and strength of domestic investment of Kyrgyzstan is not enough, so that it has to introduce foreign investment to promote GDP growth by developing these pillar industries, including investment of high technologies and capital. In the long terms, the pulling effect of consumption is lower than investment, so that Kyrgyzstan should put the key point of development direction on increase of investment to establish and complete infrastructures capable of undertaking foreign investment, to the maximum extent attract foreign investment and actively promote the gross investment level of its own country. Kyrgyzstan has very abundant natural resources but incomplete infrastructures, and its domestic conditions of resource development are not mature, so that the investors shall focus on the development of its natural resources, which can make investors favorable investment expectation; in the meanwhile, the investor should actively utilize the favorable preferential policies and material support given by Kyrgyzstan government, the unmissable optimal investment environment for our governmental departments and enterprises.

Thirdly, make great efforts to conduct international trade with Kyrgyzstan. Kyrgyzstan has a quite low development of industry, basically incapable to meet its demand for industrial products, so that it must import a large number of industrial and hi-tech products to meet domestic demands. Kyrgyzstan is the fifth export market and the third import source of our 
country. Most mechanical and electrical products, transportation equipment, light textile industrial products and daily necessities Kyrgyzstan demands are imported from our country; in addition, some of our products are exported to Russia and Kazakhstan through Kyrgyzstan. The export commodity structure of China mainly includes garment, shoes, hats, bags, suitcases, textile products and agricultural products, etc. of strong consumption rigidity, added with quite obvious advantages, so that, with the ability of Kyrgyzstan's political environment, it has more and more demand for these products, and the strong manufacture in coastal region of our country will supply continuous material supports to meet the market demand of Kyrgyzstan, and in comparison with Europe and America, Kyrgyzstan is much lighter influenced by the economic crisis and its demands for Chinese commodities is relatively objective. In terms of resource endowment, Kyrgyzstan has abundant resources but limited capacity to develop and utilize them; therefore, Kyrgyzstan requires exporting these natural resources in abundance to pay the difference of import and export, while Xinjiang of China is making efforts to establish the safe channel of energy and resources in western China, so that by utilizing this channel to import natural resources of Kyrgyzstan, we can relieve our lack of resources. Energy and resource field is the current and future key point of cooperation. See from the market demand, Kyrgyzstan mainly exports industrial and agricultural raw materials to our country, and we well build the favorable partnership between Kyrgyzstan and China for the trade between both countries by virtue of Xinjiang as the center of investment activity and goods distribution.

\section{CONCLUSION}

In general, see from the development trend of Kyrgyzstan's macro economy, due to the fact that Kyrgyzstan's economic basis is still weak, still in the initial step of industrialization, with low degree of industrialization, small additional value of industries, so that in the short term, the positive promoting function of consumption on actual GDP is larger than investment; however, in the long term, the positive promoting function of consumption on actual GDP is smaller than investment, the reason why investment effect is smaller than consumption effect in the short term mainly is that the use efficiency of capital is low and the investment structure is unreasonable, which restricts the promoting function of investment on GDP. Kyrgyzstan has a quite low development of industry, basically incapable to meet its demand for industrial products, so that it must import a large number of industrial products to meet domestic demands, which leads to trade deficit, and as a typical agricultural giant and natural resource giant per sue, Kyrgyzstan requires exporting industrial and agricultural raw materials in abundance to implement trade deficit. Therefore, we should increase industrial and hi-tech products and advanced technologies to Kyrgyzstan and investment to Kyrgyzstan industry, make great efforts to import low-price industrial and agricultural raw materials and natural resources from Kyrgyzstan to increase its strength of consumption, rapidly promote its investment capacity and improve its economic development; in the meanwhile, promote our export level to Kyrgyzstan as well as import level of raw materials and natural resources and strength of investment.

\section{REFERENCES}

[1] Fanzi. Topic on China-Kyrgyzstan Boundary Trade by Kyrgyzstan Commercial Counselor Stationed in China [J]. NEW SILK ROAD HORIZON, 2007, (06): 74-75.

[2] Xu Hui. Economic and Trade Cooperation between China and Kyrgyzstan [J]. Russian Central Asian \& East European Market, 2007,(07):27-33.

[3] Li Qin, Xu Yunxia. Exploration and Analysis on Xinjiang Devoting Great Efforts to Export to Kyrgyzstan and Countermeasures [J]. Russian Central Asian \& East European Market, 2010, (02)

[4] Hao Yan. Econometric analysis on quantitative relation among main macroeconomic variables of Hainan Province [J]. Hainan Finance, 2004 (03):29-31

[5] Zhang Yangzhi, Liu Gui. Empirical analysis on foreign trade and economic growth of Kyrgyzstan [J]. Journal of Guizhou Normal University, 2007, (1): 57-62. 